\title{
Conclusion: Taking the Long View on Medieval Disfigurement
}

Working on a project that explores the representation of and responses to acquired facial disfigurement in early medieval Europe, I have been struck by the sheer number of instances recorded in medieval evidence. The disruption of the facial features - by far the most visible of sites - resonates with medieval observers; it is threatened as a corporal punishment in legal sources, but penalized if inflicted by anyone other than the king; it features in folkloric tales, often as a warning against transgressive behavior; it is commented upon, often at length, to draw moral lessons. But almost all of this evidence comes from the pens of those observing or imagining facial disfigurement: like many apparently marginal groups in medieval society, the voices of disfigured people themselves are very seldom heard. Yet the patient acceptance of disfigurement or difference is also held up in medieval religious and secular texts as a sign of sanctity or humility before God. The medieval examples offer an opportunity to explore the ambivalence surrounding disfigurement, and try to draw out some questions regarding continuities in the history of people with disfigurements over centuries. Irina Metzler has raised the question as to whether the face-to-face society of the Middle Ages had any concept of disability, and asks whether individuals could have had a "disabled identity." In the present study, the social stigma associated with acquiring a visible facial injury in the early Middle Ages only seems to become an "identity" in legal records of the thirteenth century, when claiming to be a "maimed man"-a status that presumably needed to be permanent-enabled plaintiffs to avoid trial by physical combat. It is certainly the case that the number of examples of recorded

P. Skinner, Living with Disfigurement in Early Medieval Europe, DOI 10.1057/978-1-137-54439-1_8 
disfigurement increases as we move from the sixth century to the twelfth, and narrative accounts from the latter part of our period do appear to have focused in greater detail on facial appearance than earlier writers. But the exhaustive lists of personal injuries to the head and face contained in early medieval lawcodes suggest that overall levels of concern about facial appearance remained pretty constant in these centuries. The major change - in evidential terms at least - came about with the explosion of medical writings rediscovered in the twelfth century, and a concomitant and well-documented trend toward identification and classification precipitated by Western Europe's engagement (including violence) with the Muslim world.

A substantial proportion of the instances of disfigurement recorded occurs in prescriptive material, and this needs to be acknowledged: the project of recording how people lived with disfigurement relies primarily on actual cases where we know the disfigurement happened. Yet this study has only been able to turn up two or three cases for the entire period where some form of first-person reflection takes place-Wipert, Thietmar, and Walchelin-all three quite late, and all three drawing specific lessons from their different appearance. The first question for further work on disfigurement is thus the nature of the records: at what point will these change from mainly looking at people with disfigurements, to a mixture of observations and accounts of the lived experience of looking different? Is the autobiographical account of becoming and being disfigured confined to the most recent century, or are clues to living with disfigurement embedded in earlier letters, diaries and narratives? The early medieval sample privileges reports of deliberate disfigurement over accounts of accidental injury, and focuses almost entirely on when the appearance of male, elite figures, from the lay or clerical sphere, was temporarily or permanently altered. Many lived with their disfigurement afterwards, but it is striking just how many facial injuries were associated with the word "ridicule," and how this specific term persists in sources across our entire period. ${ }^{2}$ In a medieval culture that valued honor and face, being laughed at, or being the object of not-so-amusing comments, was just as much an injury as physical damage.

What is missing, quite strikingly, is any expression of disgust: here, modern theorists have introduced a concept that is largely absent from the medieval sources. William Ian Miller may relate modern disgust responses to earlier periods, but the "barbarically loathsome" actions of a few were presented with horror expressed at the actions, not their results. ${ }^{3}$ Authors 
might express horror and pity, and share with the reader the spectacle of certain acts of mutilation at somewhat greater length than was entirely necessary (my "textual staring"), but they do not describe the aftermath as "disgusting." There was a spectrum associated with the aftermath too: a disfigurement without associated impairment and one with impairment (of sight, hearing or speech) were classified differently in some of the early laws, and perhaps ridicule shaded into sympathy for the latter category. This distinction has also been made in historiographical practice: only impairment makes it into histories of disability or medical practice, whilst "simple" disfigurement is largely unnoticed and lacks sustained attention from scholars.

Yet, inflicting a deliberate disfigurement was a highly political act, and this study has brought out the significance of mutilation-by-proxy, the attacking of dependents as a means of symbolizing the loss of control or status of the person meant to protect them, be it a king, or a father or-in the specific case of women-a husband. Of course, reports of such attacks still focus our attention on the intended target: the dependents are, often, unfortunate collateral damage (and those mutilated very young were the most damaged of all, facing a lifetime of marginalization). But even the proxies need to be significant in some way-there was no point mutilating a peasant tenant if you wanted to insult the king. One might in fact interpret the threatened mutilation of adulterous women in several lawcodes as a warning to their husbands about the potential shame they could suffer at having failed to assert adequate control and protection over their wives, even if this is not explicitly stated in the clauses themselves. Work on medieval violence has picked up on the fact that wives and dependents might be caught up in the downfall of their menfolk or leaders, and toward the twelfth century we certainly see more instances of deliberate mutilations as weapons of humiliation. Whether this is a product of the increase in available written evidence is unclear: the further escalation in the severity of facial violence in the thirteenth century, noted at the start of this study, suggests that this is not simply a matter of the multiplication of texts, but represents a shift away from killing to wounding as a means of settling scores. A question for future research, therefore, might focus on when reports begin of more "ordinary" people with acquired disfigurement (such as some of those documented in the Eyre courts), and explore the reasons for this change.

The stories that disfigurement generated for the early medieval, largely clerical, writers who recorded such incidents seem to fit within something 
of a predetermined set of parameters drawn from the Bible. And, for many of our writers, the piteous spectacle of those mutilated, or about to be, was an opportunity for others to provide charity, or intervene to plead mercy. It is never stated outright, but disfigurement was, to the elite community we can hear and read about, akin to social death. In some cases the power of a disfigured person's family could shield them from the worst assumptions about their condition, but such protection only lasted as long as they lived; it is interesting that we have a couple of cases of damnatio memoriae, whereby later authors, commenting on the same set of circumstances, draw much more robustly negative conclusions about whose fault the disfigurement was (the cases of Young Charles and the Saxon pirate raids of 994 are good examples).

Another issue for historians of disfigurement, therefore, might be how long the framing of disfigurement within religious terms of reference lasted. At what point did the religious framework for understanding disfigurement (act of God, act of wicked people, own fault, disbars further religious or political activity, engenders patience and humility), which is so prominent in the evidence from the early Middle Ages, lessen or disappear, and what replaced it? Although this study ends around $1200 \mathrm{CE}$, I would hazard a guess that later medieval authors understood and presented disfigurement in very similar ways to those discussed here. Even if more and better skincare remedies (and cover-ups) were being produced, and texts theorizing about surgical repair to the face were being written and circulated by the fifteenth century, the fact remains that faith provided a means of articulating and dealing with the trauma of an acquired disfigurement. Theology Professor Stephen Pattison has recently argued that the Protestant Reformation saw a shift in emphasis from seeing the face of God to hearing and obeying God's word, that is, the opportunity for "face" to play a role in human relations with each other and the divinity diminished sharply, and remains absent today. ${ }^{4}$ This hypothesis, convincingly argued, would reward further investigation by historians. Pattison's comments on the isolation, exclusion and shame of those who cannot participate in facial transactions, whether because of disfigurement or neurological conditions impairing facial recognition, resonate loudly with the historical experiences discussed in the present study.

So what about gender? The reality of the early medieval texts is that the vast majority of cases feature, or can be assumed to feature, the disfigurement of men. The minority sample of women is itself interesting in that the type or form of the disfigurement they suffer differs from the men: usually specific, inflicted damage to appearance of the face, rather than mutilations 
of ears or blinding. Males, as we might expect, are also frequently injured in war and at close quarters by swords, clubs and axes. If this did not result in a fatal injury, it left a mark that, I have argued, shamed rather than distinguished the recipient. Rosemary Garland-Thomson has suggested that acquired impairment in adult, white males re-classifies them as among the more socially disadvantaged, who, in the modern American society she was discussing, consist of women and people of color. Depending on the level of disfigurement - and in the medieval spectrum I have explored, this ranges from broken noses and bramble scratches leaving a facial scar on one end, to permanent removal of the eyes or other facial features such as lips, noses or ears on the other-acquired facial disfigurement, too, had the potential to feminize a male victim, particularly if he had been socially active and in the prime of life. The ability to wage war, in particular, was a key feature of elite medieval masculinity (even among some clerics). The dependence inherent in being cared for after disfigurement itself removed a person from their "normal" lives, and whilst they might recover physically, the visible change in their faces clearly provoked interest and inquiry. The rehabilitation of war-wounded men does not feature in the sources, suggesting that this was a process best done in private, and out of sight. It is unlikely to be coincidental that our three first-person accounts are all by clerics, whose masculinity was not compromised in such a devastating way by their condition.

A third question, therefore, centers on the gender imbalance in disfigurement cases. Do women remain in the minority over time, or has disfigurement increasingly become a weapon used only against women? Medieval medical theory, following Aristotelian thought, classified the female body as damaged or lacking anyway. The medieval judicial penalty of castration, threatened and sometimes inflicted upon men, was not available for women, and this may explain why we have instances in medieval law of the female face being a target for punishment and abuse. But what is interesting to me is how reports of female miscreants foreground their sexual morality, even when the deed for which they are being punished might appear to be a whole lot more serious. In fact, medieval authors have a hard time imagining women being violent, and so might equally well ignore evidence of violence against women as trivial compared with the honor games played out between men.

Taking the long view can sometimes be a risky business-medieval specialists might cry "anachronism" when the insights of modern social sciences or cultural studies are applied to medieval texts—or worse still this is "medievalism" and not "medieval studies" (I speak tongue in cheek here; the burgeoning field of medievalism is both intriguing and challenging). 
And some of the constraints visible in even this brief report of medieval attitudes toward disfigurement might seem too far distant from modern concerns and priorities to enable a genuine cross-period dialogue that can provide insight both ways. James Partridge, founder and director of the UK charity Changing Faces, stated, in a recent online campaign against an offensive advertisement campaign, that "Changing Faces is determined to challenge any example of prejudicial portrayal because we are not living in the Middle Ages [my emphasis]." But medieval attitudes to disfigurement were not so entrenched as to allow me to let his comment go unchallenged. As in modern contexts, reactions were fluid, contingent upon the circumstances of acquisition, and community acceptance of a disfigured face was freighted with similar anxieties about the source of the damage. Another link between the medieval and the modern, I contend, is the fact that disfigurement was and remains a highly-individualized experience: there is a great deal of resistance in contemporary discourse to the idea that facial difference is an undifferentiated, collective experience, and the same appears to be true of medieval cases: the stories are always personal.

There are differences of course. Unlike the medieval past, disfigurement in the present can-provided this is what the patient wants-be mitigated by surgical and cosmetic intervention. And the much wider access to literacy and media means that the voices of people with disfigurements can be heard. But what I would suggest is that we need to take the long view in order to highlight the fact that, whilst the medical ability to address disfigurement has taken enormous strides, and the psychological effects of sudden, acquired disfigurement are now much better understood, reconstructing the history of disfigurement can expose-much as other minority history campaigns have done-the high and low points against which to measure our own, current social attitudes and prejudices.

\section{Notes}

1. Irina Metzler, Disability in Medieval Europe: Thinking about Physical Impairment during the High Middle Ages (London: Routledge, 2006), pp. 5-9.

2. Ibid., p. 163, notes the same language in the thirteenth-century miracles of St Elizabeth of Hungary, for example. 


\section{William Ian Miller, The Anatomy of Disgust (Cambridge, MA: Harvard University Press, 1997), 11-22. \\ 4. Stephen Pattison, Saving Face: Enfacement, Shame, Theology (Farnham/Burlington, VT: Ashgate, 2013), 2 and 51-75.}

Open Access This chapter is distributed under the terms of the Creative Commons Attribution 4.0 International License (http://creativecommons.org/licenses/by/4.0/), which permits use, duplication, adaptation, distribution and reproduction in any medium or format, as long as you give appropriate credit to the original author(s) and the source, provide a link to the Creative Commons license and indicate if changes were made.

The images or other third party material in this book are included in the work's Creative Commons license, unless indicated otherwise in the credit line; if such material is not included in the work's Creative Commons license and the respective action is not permitted by statutory regulation, users will need to obtain permission from the license holder to duplicate, adapt or reproduce the material.

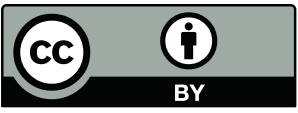

